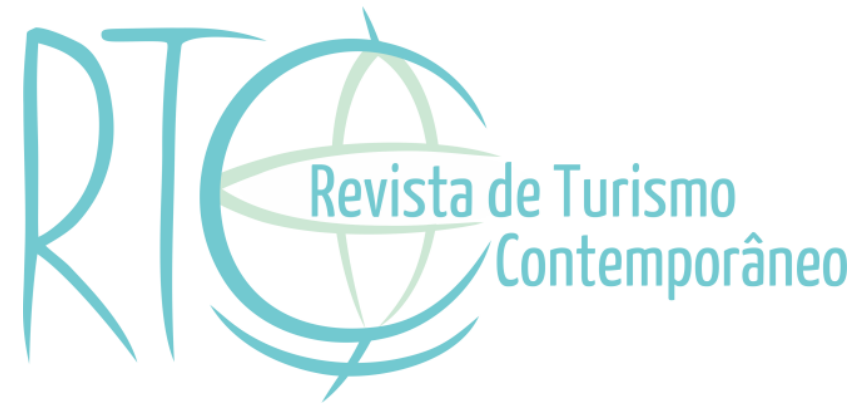

\title{
Contribuições de Leiper, Wahab e Cuervo para a abordagem sistêmica do turismo
}

\section{Contributions of Leiper, Wahab and Cuervo to the} systemic approach to tourism

Débora Goes Urano

Mestranda pelo Programa de Pós-Graduação em Turismo PPGTUR-UFRN. Natal/RN, Brasil. E-mail: debby104@hotmail.com 


\section{RESUMO}

A expansão e intensificação da atividade turística em todo mundo leva a uma crescente necessidade de estudos para uma melhor compreensão, análise e teorização do fenômeno. Este artigo busca analisar as contribuições dos autores Raimundo Cuervo, Salah Eldin Abdel Wahab e Neil Leiper, que permearam o debate a cerca dos estudos do turismo durante o período compreendido entre 1960 e 1980; e que culminou na visão sistêmica do turismo. A metodologia utilizada se caracteriza como um estudo teórico, bibliográfico e exploratório. A pesquisa foi realizada por meio do levantamento de dados acerca da vida e obra dos autores, e da análise de suas principais obras, identificadas como influentes para o surgimento da abordagem sistêmica. $\mathrm{O}$ estudo mostrou que esses autores tiveram grande contribuição por romperem com o pensamento compartimentado que caracterizava a época, e propor uma análise baseada no conceito de sistema através de uma visão macroscópica do todo e da interação entre as partes e com o meio, colocando o homem, e seu deslocamento, como elemento principal do turismo.

Palavras-chave: Cuervo. Leiper. Wahab. Paradigma sistêmico.

\section{ABSTRACT}

The expansion and intensification of tourism worldwide leads to an increasing need for studies to a better understanding, analysis and theorizing of the phenomenon. This paper analyzes the contributions of the authors Raimundo Cuervo, Salah Eldin Abdel Wahab and Neil Leiper, who permeated the debate about the studies of tourism during the period between 1960s and 1980; that culminated in the systemic view of tourism. The methodology used is characterized as a theoretical, bibliographic and exploratory study. The research was conducted through data survey about the authors' life and work, and the analysis of their major works, which were identified as influential in the emergence of the systemic approach. The study showed that these authors had great contribution by breaking with the segmented thinking that characterized the period, proposing an approach based on the concept of systems analyzing it through a macroscopic view of the whole and the interaction between the parties and with the environment, placing the man, and his displacement, as the main element of tourism.

Keywords: Cuervo. Leiper. Wahab. Systemic paradigm. 


\section{INTRODUÇÃO}

O turismo se tornou uma atividade marcante da sociedade contemporânea. Os deslocamentos humanos que caracterizam o fenômeno turístico transformam economias, paisagens e culturas em todas as localidades do mundo. Busca-se, cada vez mais, compreendê-lo e analisá-lo dentro de sua complexidade, envolvendo todas as áreas com as quais o mesmo está relacionado. Assim, torna-se necessária a construção de um território epistêmico que consiga pensar e teorizar o turismo enquanto experiência multidimensional e complexa englobando os mais diversos aspectos (Azevedo, 2013).

A epistemologia do turismo vem ganhando importância nos estudos sobre turismo a partir da década de 1990, buscando a compreensão da construção do conhecimento acerca do fenômeno, ao invés de focarem apenas nas questões práticas da atividade como gestão, planejamento, entre outros (Lohmann, \& Panosso Netto 2008). Cabe à epistemologia, uma revisão do conhecimento em relação ao turismo, auxiliando na explicação do fenômeno e fornecendo bases científicas seguras (Panosso Netto, 2005). Nesse sentido, ao longo do tempo algumas tentativas de construção epistemológica foram feitas por alguns autores com o intuito de melhor compreender o conhecimento acerca do turismo, assim como o próprio fenômeno.

MacIntosh e Goeldner (2000) (como citados em Hererra 2013) na sua obra "Tourism, Principles, Practices and Philosophies" aponta nove abordagens que são feitas dentro dos estudos do turismo. A abordagem institucional (1), realizada por instituições que trabalham com o turismo; abordagem através do produto turístico (2), sua produção, comercialização e consumo; abordagem histórica (3), por meio da evolução da atividade; abordagem administrativa (4), através da gestão de negócios turísticos; abordagem econômica (5), que estuda os impactos econômicos e de desenvolvimento da atividade; além da sociológica (6); geográfica (7); e interdisciplinar (8). Por fim, o autor aponta a existência de uma abordagem sistêmica (9), a qual o autor coloca como a ideal para o estudo do fenômeno, e na qual o mesmo diz fazer parte.

Acerenza (2002), por sua vez, aponta a existência de quatro enfoques principais de análise do turismo: o econômico, o social, o psicológico e o sistêmico. O enfoque econômico que vê o turismo como um fenômeno econômico foi trabalhado, principalmente, no que o autor chama de Escola Berlinesa. O enfoque social, coloca o homem como o elemento mais importante do fenômeno, sendo o enfoque principal da Escola Francesa. O enfoque 
psicológico analisa o fenômeno a partir das motivações que levam aos deslocamentos do indivíduo, introduzido pela Escola Polonesa.

Por último, Acerenza afirma existir o enfoque sistêmico. Este enfoque entende o turismo como um fenômeno complexo e pretende analisá-lo em sua totalidade, sendo fundamentado na Teoria Geral dos Sistemas. Ele afirma que:

\footnotetext{
esse enfoque (sistêmico) não só oferece uma explicação razoável sobre a estrutura e funcionamento do fenômeno, mas que, além disso, permite integrar o conhecimento que as diversas ciências fornecem sobre seus componentes, para conhecer assim o comportamento do conjunto. (Acerenza, 2002, p.193)
}

Nesse sentido, o autor reconhece a importância dos outros enfoques para a construção do conhecimento do turismo, mas destaca que eles permitiam, apenas, uma análise de aspectos parciais do fenômeno, o que limitava a compreensão do turismo em toda a sua complexidade. Assim, a introdução da visão sistêmica no turismo visa superar essas limitações abordando o turismo em sua totalidade, possibilitando a identificação dos diversos elementos constituintes do fenômeno turístico, e a compreensão das relações entre estes elementos e destes com o meio. Os autores Raymundo Cuervo e Neil Leiper são apontados como os pioneiros nessa abordagem (Acerenza, 2002).

Panosso Netto (2005), na sua tentativa de teorização dos estudos do turismo, baseia-se em Kuhn (2001) para apresentar três fases de abordagem do turismo. De acordo com Kuhn (2001) o avanço da ciência não ocorre de forma cumulativa, mas por meio de um processo de transição de um paradigma a outro, que acontece por meio da ruptura do paradigma vigente para um novo, o que ele chama de revoluções científicas. Para Kuhn, um paradigma seria os valores e conceitos teóricos aceitos pela comunidade científica por um período de tempo. Deste modo a mudança de paradigma leva a mudança do próprio mundo, pois "após as revoluções os cientistas reagem a um mundo diferente" (Kuhn, 2001, p.146).

Para Panosso Netto (2005), a primeira fase é a pré-paradigmática, que se configura nas primeiras tentativas de análise teórica do turismo e se caracteriza por não ter conseguido criar uma escola de pensamento capaz de formar um paradigma aceito pela comunidade acadêmica. Essa fase é formada por um grupo de autores como Luiz Fuster, Walter Hunziker, A. J. Burkart e S. Medilk. A segunda fase consiste no que o autor denomina de fase paradigma do sistema de turismo, devido ao fato de o sistemismo "ter grande difusão, abrangência e utilização nos estudos do turismo e, até o momento, é a teoria que melhor explica a dinâmica do turismo, apesar de ainda conter elementos que dificultam sua compreensão" (Panosso 
Netto, 2005, p.45). Como autores representantes do paradigma sistêmico encontram-se Neil Leiper, apontado como o autor que introduziu com sucesso a Teoria Geral de Sistemas nos estudos turísticos, além de Mário Beni, Roberto Boullón e Alberto Sessa.

A terceira fase consiste na fase Novas Abordagens, que busca explicar as lacunas apresentadas pela visão sistêmica propondo novas e inovadoras formas de análise do turismo, que possam superar o paradigma vigente. Nessa fase encontram-se autores como Jafar Jafari e John Tribe. Entre essas três fases, o autor aponta, ainda, a existência de áreas de transição, na qual encontram autores que parte de conceitos de uma fase para introduzirem aspectos a serem abordados na fase seguinte. $\mathrm{Na}$ fase de transição entre as fases pré-paradigmática e paradigma sistêmico, encontram-se os autores Panosso Netto (2005) enquadra os autores Raimundo Cuervo e Salah- Eldin Abdel Wahab na área de confluência e transição entre a fase pré-paradigmática e a fase do paradigma sistêmico. Estes encontram-se nessa área, pois introduziram a análise do turismo através de um sistema, sem ter, no entanto, tido tanta difusão e influência na época para a construção de um paradigma. Já na fase de transição entre o paradigma sistêmico e as novas abordagens encontram-se autores como J. J. Martinez, Kripperdorf e Molina.

Dentro os diferentes enfoques percebidos por diversos autores que buscaram uma teorização dos estudos do turismo. Percebe-se a forte contribuição do sistemismo. O mesmo é apontado como o enfoque mais aceito, utilizado e aperfeiçoado por teóricos do turismo pelo fato de analisar o turismo em toda a sua complexidade e através da relação entre seus elementos e com o meio. Essa abordagem tem como principal fundamento a Teoria Geral dos Sistemas apresentada por Bertalanffy, na década de 1940. Instigado por evidentes lacunas em pesquisas na área da biologia, o autor defendia novas formas de pensar que transcendessem os métodos das ciências clássicas. Nesse sentido, ele apresenta uma concepção de organização dos organismos vivos como um sistema compreendendo toda a sua totalidade e a relação entre as partes, defendendo que o objetivo principal da biologia era compreender os princípios dessa organização em diferentes níveis Bertalanffy (1968). Ele reconheceu, ainda, que os organismos vivos são sistemas abertos que precisam "se alimentar de um contínuo fluxo de matéria e de energia extraída do seu meio para permanecerem vivos" (Capra, 1996, p. 44), sofrendo, assim, forte influência do meio em que estão inseridos.

No pensamento sistêmico, há uma inversão na relação entre as partes e o todo, percebendo que "as propriedades das partes não são propriedades intrínsecas, mas só podem ser entendidas dentro do contexto maior" (Capra, 1996, p. 36). Nesse sentido, as relações entre as partes se torna mais importante do que as partes em si, o que se contrapõe a 
concepção do paradigma científico cartesiano da época, que acreditava que em um fenômeno complexo, o todo podia ser analisado a partir das propriedades de suas partes. Como afirma Capra:

\begin{abstract}
$\mathrm{Na}$ visão mecanicista, o mundo é uma coleção de objetos. Estes, naturalmente, interagem uns com os outros, e, portanto, há relações entre eles. Mas as relações são secundárias [...] $\mathrm{Na}$ visão sistêmica, compreendemos que os próprios objetos são redes de relações, embutidas em redes maiores. Para o pensador sistêmico, as relações são fundamentais. As fronteiras dos padrões discerníveis ("objetos") são secundárias (Capra, 1996, p. 37).
\end{abstract}

O pensamento sistêmico constituiu, assim, uma mudança de paradigma, rompendo com o pensamento mecanicista e compartimentado da época, permitindo um novo olhar para a compreensão de fenômenos complexos nos mais diferentes campos de conhecimento.

A Teoria Geral dos Sistemas trouxe princípios que poderiam ser aplicados a diferentes sistemas vivos, compreendendo, por exemplo, organismos individuais, sistemas sociais e ecossistemas, o que possibilitou a sua utilização em várias áreas do conhecimento. Nas palavras de Bertalanffy:

It seems, therefore, that a general theory of systems would be a useful tool providing, on the one hand, models that can be used in, and transferred to, different fields, and safeguarding, on the other hand from vague analogies which often have marred the progress in these fields (Bertalanffy, 1968, p. 34,).

Somente a partir do começo da década de 1970, que o pensamento sistêmico começa a ser introduzido nos estudos do turismo (Herrera, 2013). Acerenza (2002), no entanto, aponta o mexicano Raimundo Cuervo como pioneiro nesta abordagem sistêmica através do ensaio "El turismo como médio de comunicación humana”, publicado em 1967. Este trabalho, no entanto não foi muito disseminado. O egípcio Salah Eldin Abdel Wahab foi outro autor que durante essa época introduziu a concepção de sistema na análise do turismo, na sua obra "Introdução à administração do turismo" (Panosso Netto, 2005). No entanto, somente em 1979, com o trabalho de Neil Leiper denominado "The Framework of tourism: towards a definition of tourism, tourist, and the tourist industry", publicado na Annals of Tourism Research, é que a Teoria Geral dos Sistemas é efetivamente introduzida nos estudos do turismo. Na referida obra, o autor propõe um modelo conceitual e gráfico para o sistema turístico (Acerenza, 2002; Panosso Netto, 2005; Herrera, 2013). O trabalho de Leiper serviu de base para a construção de vários outros modelos de sistema do turismo.

Nesse sentido, surge o anseio de analisar as contribuições destes autores que permearam o debate acerca dos estudos do turismo durante o período compreendido entre os 
anos de 1960 e 1980, propondo uma nova forma de compreensão do fenômeno para a época, introduzindo o sistemismo nos estudos do turismo. Os autores identificados como mais relevantes, neste período, a partir da revisão de literatura sobre a abordagem sistêmica do turismo foram Raimundo Cuervo, Salah Eldin Abdel Wahab e Neil Leiper.

A análise das obras destes autores torna-se relevante na medida em que permite uma maior compreensão do surgimento do pensamento sistêmico nos estudos do turismo e fortalece a construção epistemológica dessa área de estudo, consolidando o conhecimento e teorias para estudos futuros.

\section{METODOLOGIA}

Para a análise das contribuições de Raimundo Cuervo, Salah Eldin Abdel Wahab e Neil Leiper no surgimento da visão sistêmica nos estudos do turismo, seguiram-se três etapas de pesquisa. Inicialmente, foi realizado um levantamento de dados a cerca da vida profissional e obras publicadas pelos autores por meio de pesquisas em livros, periódicos nacionais e internacionais e ferramentas de busca na Internet como o Google. Devido ao difícil acesso a dados sobre o autor Raimundo Cuervo, o levantamento de dados sobre o mesmo foi realizado por meio de referências suas em obras de outros autores.

A segunda etapa da pesquisa consistiu na identificação das principais obras que abordam o turismo como sistema. Dessa forma, foram escolhidas para a análise a obra de Cuervo "El turismo como médio de comunicación humana" (1967); a obra de Wabah, "Introdução a administração do turismo" (1988) e a obra de Leiper "The Framework of tourism: towards a definition of tourism, tourist, and the tourist industry"(1979). Como não foi possível ter acesso à obra de Cuervo, sua análise foi feita por meio de citações da referida obra por outros autores.

$\mathrm{Na}$ terceira etapa da pesquisa foi realizada a análise das obras citadas acima, buscando uma maior compreensão das influências sofridas pelos autores para a construção das abordagens e conceitos apresentados nas obras. E, principalmente, para um maior entendimento dos pensamentos destes autores através do diálogo entre suas obras.

Nesse sentido, o estudo apresenta-se como, essencialmente, teórico, pois "não tem por objetivo uma utilização prática dos resultados, mas sim o enriquecimento do conhecimento científico" (Santos, 2011, p.86). Além disso, caracteriza-se por ser uma pesquisa de cunho bibliográfico, tendo em vista que busca analisar e interpretar os dados e informações coletados nas referidas obras (Leite, 2008).Vale ressaltar que a pesquisa tem um caráter 
exploratório, pois busca proporcionar maior familiaridade com o problema, de forma a tornálo mais explícito ou formular hipóteses (Gil, 1991). De acordo com Leite, "as pesquisas exploratórias tem como objetivo dar ideias novas, construir hipóteses, possuindo assim estrutura bastante flexível" (Leite, 2008, p.65).

Para a análise dos textos selecionados, primeiro, foi realizada uma leitura analítica (Gil, 1985) para sumarizar e ordenar as informações apresentadas no texto. Essa leitura analítica permitiu a identificação de temas em comum abordados pelos atores em cada texto, e definidas como categorias de análise, a saber: a concepção de turismo, elementos que constituem o turismo e modelo proposto de sistema turístico. Após a identificação destes temas, foi feita uma leitura interpretativa (Gil, 1985), que buscou em cada categoria de análise relacionar as ideias expressas nas obras e interpretar o significado destas ideias, analisando-as enquanto contribuição para a construção do conhecimento do turismo.

Vale ressaltar que a análise e discussão dos resultados apresenta-se por autor, por entender que a análise realizada dessa forma permite uma visão geral do pensamento de cada autor, ao mesmo tempo que, permite fazer uma relação entre os autores e entre estes e a construção do pensamento sistêmico dentro do turismo.

\section{ANÁLISE DISCUSSÃO DOS RESULTADOS}

\subsection{Raimundo Cuervo}

O engenheiro Raimundo Cuervo é apontado por Acerenza (2002) como sendo o pioneiro a propor uma análise do turismo por meio de um sistema. Essa proposta de análise do turismo foi apresentada no livro "El turismo como médio de comunicación humana", publicado em 1967 pelo Departamento de Turismo do Governo do México. Cuervo deu um tratamento matemático ao seu sistema, utilizando a álgebra booleana, que se baseia na teoria dos conjuntos. Cuervo defendia que o conceito de sistema permitia o entendimento científico dos mais diversos fenômenos e que se tornava necessário a utilização do mesmo para a compreensão do conceito de turismo. Tendo em vista, que este era muito limitado devido à falta de métodos e meios apropriados para trabalhar a diversidade de elementos que se interrelacionam no turismo Cuervo (1967 como citado em Acerenza, 2002). Neste sentido, o ator manifesta a necessidade de analisar o turismo por meio do conceito de sistema devido à complexidade que caracteriza o fenômeno. 
Para Cuervo (1967 como citado em Lohmann \& Panosso Netto 2008, p.30). o turismo "é um conjunto bem definido de relações, serviços e instalações que se geram em virtude de certos deslocamentos humanos". O termo conjunto é entendido dentro desse conceito, de acordo com Acerenza (2002), como uma "coleção bem definida de objetos, sem que esses, necessariamente, tenham que ser da mesma natureza, nem similares, basta simplesmente que a coleção esteja bem definida" (Acerenza, 2002, p.195). Esse grande conjunto referente ao turismo seria dividido em subconjuntos ${ }^{1}$, que por sua vez seriam divididos em outros subconjuntos, que consistiriam nos serviços e instalações relacionadas com a atividade turística.

A Figura 1 representa o sistema turístico de Cuervo (1967). Para o autor, o conjunto S de seu sistema turístico se refere aos deslocamentos humanos reversíveis. Os mesmos são deslocamentos temporários em que o indivíduo sai de seu local de residência habitual, temporariamente, e retorna para o mesmo (Panosso Netto, 2005).

Dessa forma, Cuervo (1967 como citado em Lohmann \& Panosso Netto, 2008) aponta o ser humano, na figura de turista, e o seu deslocamento como sendo o elemento principal para a promoção das relações e interações dos subconjuntos que compreendem o turismo. E, por consequência, converte o mesmo em um sistema.

Figura 1: Sistema Turístico de Cuervo

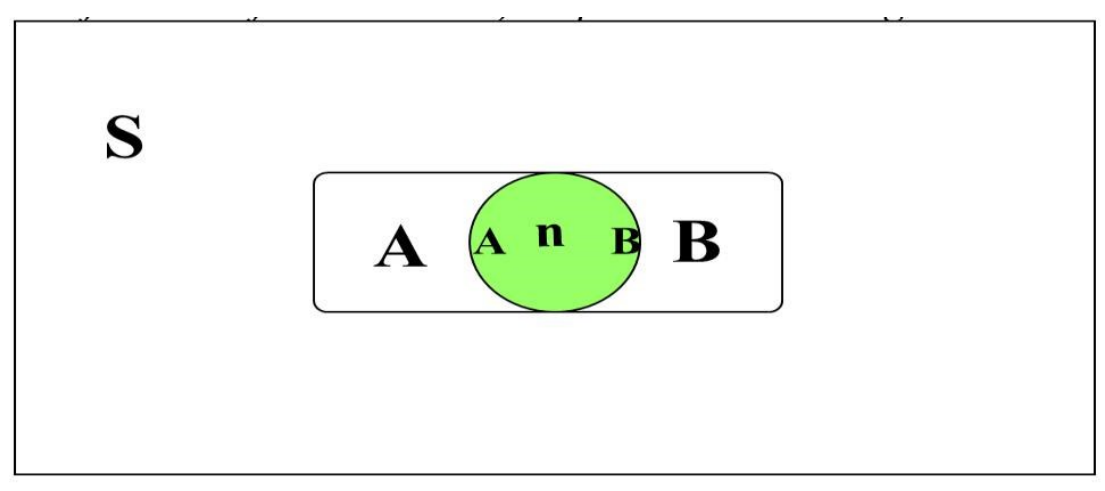

Fonte: Panosso Netto, 2005

Lohmann e Panosso Netto (2008) mostram, ainda, que Cuervo (1967) afirma que a função do conjunto do turismo é a da comunicação, e que por meio deste, caso haja um correto funcionamento do sistema, é capaz de transmitir mensagem positiva para a promoção da paz entre os povos.

1 De acordo com Acerenza (2002), Cuervo identificou os seguintes subconjuntos: transportes; alojamento; serviços de alimentação; centros de lazer; estabelecimentos comerciais relacionados a atividade turística; e serviços complementares como agências de viagens, locadoras de carro, etc. 
Se, então, aceitamos que, mediante a viagem, ocorre a comunicação, podemos aceitar a hipótese válida que o conjunto turismo é um sistema, e que podemos predeterminar para esse sistema uma função dada que, neste caso, é a da comunicação (Cuervo 1967 como citado em Lohmann \& Panosso Netto, 2008, p.31).

O estudo de Cuervo é reconhecido como o pioneiro a trazer uma abordagem sistêmica à análise do turismo. No entanto, o estudo não foi muito divulgado na época. Segundo Acerenza (2002), isso ocorreu devido ao fato do autor ter dado ao assunto um tratamento matemático, o que não é muito comum nos estudos do turismo. Nesse sentido, apesar de introduzir à análise do turismo a concepção de sistema, o estudo não teve tanta influência para a construção de um novo paradigma (Panosso Netto, 2005).

\subsection{Salah Eldin Abdel Wahab}

Salah Wahab nasceu no Egito. Formado em direito, obteve dois doutorados, um em Ciências Jurídicas e, outro, em Direito Internacional Comparado pela Universidade de Cornell, Estados Unidos. Iniciou sua relação com o turismo quando assumiu a direção geral da Organização Nacional de Turismo e Hotéis, em 1963. No ano de 1969, assumiu a presidência da Federação Nacional de Turismo e Hotelaria e Câmara de Comércio Hoteleiro. A partir de então ocupou os mais diversos cargos relacionados ao turismo como consultor das Nações Unidas e da Organização Mundial de Turismo em política e desenvolvimento do turismo; Sub-Secretário de Estado do Turismo e Vice-Ministro para o Desenvolvimento do Turismo no Ministério da Habitação e Desenvolvimento. Faleceu em Abril de 2009 (International Academy for the Study of Tourism, 2009)

$\mathrm{Na}$ academia, trabalhou como Professor de Turismo no Centro Internacional de Treinamento em Turim (Itália) da Organização Internacional do Trabalho, como Professor de Gestão em Turismo na Faculdade de Turismo e Hotelaria na University of Alexandria; e como Professor visitante da George Washington University. Foi um dos fundadores da Academia Internacional para Estudos do Turismo (International Academy for the Study of Tourism, 2009).

O autor publicou diversas obras no decorrer do seu trabalho junto ao turismo como Managerial Aspects of Tourism (1975); Tourism Marketing (1976); Studies in Tourism Planning (1979); e Elements of State Policy (with special emphasis on developing countries) (1974). 
Uma, de suas principais obras é Introdução à administração do turismo: alguns aspectos estruturais e operacionais do turismo internacional: teoria e prática (traduzido para o português), publicado em 1975. Nesta obra, Wahab (1988) trata o turismo como um fenômeno referente ao movimento de pessoas, composto por três elementos: o homem (elemento humano como autor do ato de turismo), o espaço (elemento físico, necessariamente coberto pelo próprio ato) e o tempo (elemento temporal que é consumido pela própria viagem e pela estada no local de destino). Para o autor, sem esses elementos não existe ato turístico.

Panosso Netto (2005) aponta que a visão de turismo de Wahab foi algo inovador para a época, pois coloca o homem com elemento principal. No entanto, vale ressaltar que Cuervo (1967), como foi visto, anteriormente, em sua obra de 1967, também, colocou o ser humano e o seu deslocamento, como elemento principal da existência do sistema turístico.

Wahab define o turismo como um sistema associado à sociosfera devido à relação de dependência entre seus vários componentes.

O turismo na sua forma atual representa um sistema associado à sociosfera. Isto se deve principalmente à interdependência e à interação entre seus vários componentes, que visando a uma indústria de turismo mais "saudável", devem funcionar coerentemente. (Wahab, 1988, p. 16)

Sendo a sociosfera o conjunto de instituições políticas, econômicas e culturais que predominam em uma sociedade (Aledo, 2001); o turismo na visão de Wahab, além da interação entre seus componentes, interagiria com o ambiente econômico, político e cultural em que está inserido.

O autor coloca que um sistema é composto por duas partes: uma estática, denominada por ele de "descrição de seu estado", em um determinado momento; e uma dinâmica, que seria a descrição dos estados nas dimensões de espaço e tempo. É devida a dinâmica dos sistemas que pode-se projetar cenários futuros a partir do presente.

Nesse sentido, Wahab coloca que o turismo é composto de dois fatores, o estático e o dinâmico. $\mathrm{O}$ fator estático compreende a permanência e estadia no local do destino. E o fator dinâmico compreende os estados sucessivos nas dimensões espacial e temporal, os quais o turista está sujeito a partir do momento em que decide viajar.

Devido ao fato de Wahab não apresentar um modelo gráfico de seu sistema turístico, Panosso Netto (2005) constrói um modelo referencial de acordo com seus estudos apresentado na Figura 02. Na figura pode ser observado que o sistema turístico de Wahab 
encontra-se dentro da sociosfera e é caracterizado pela dinâmica dentro das dimensões espaço e tempo, tendo o homem como centro.

Figura 02: Possível modelo referencial do sistema turístico de Wahab proposto por Panosso

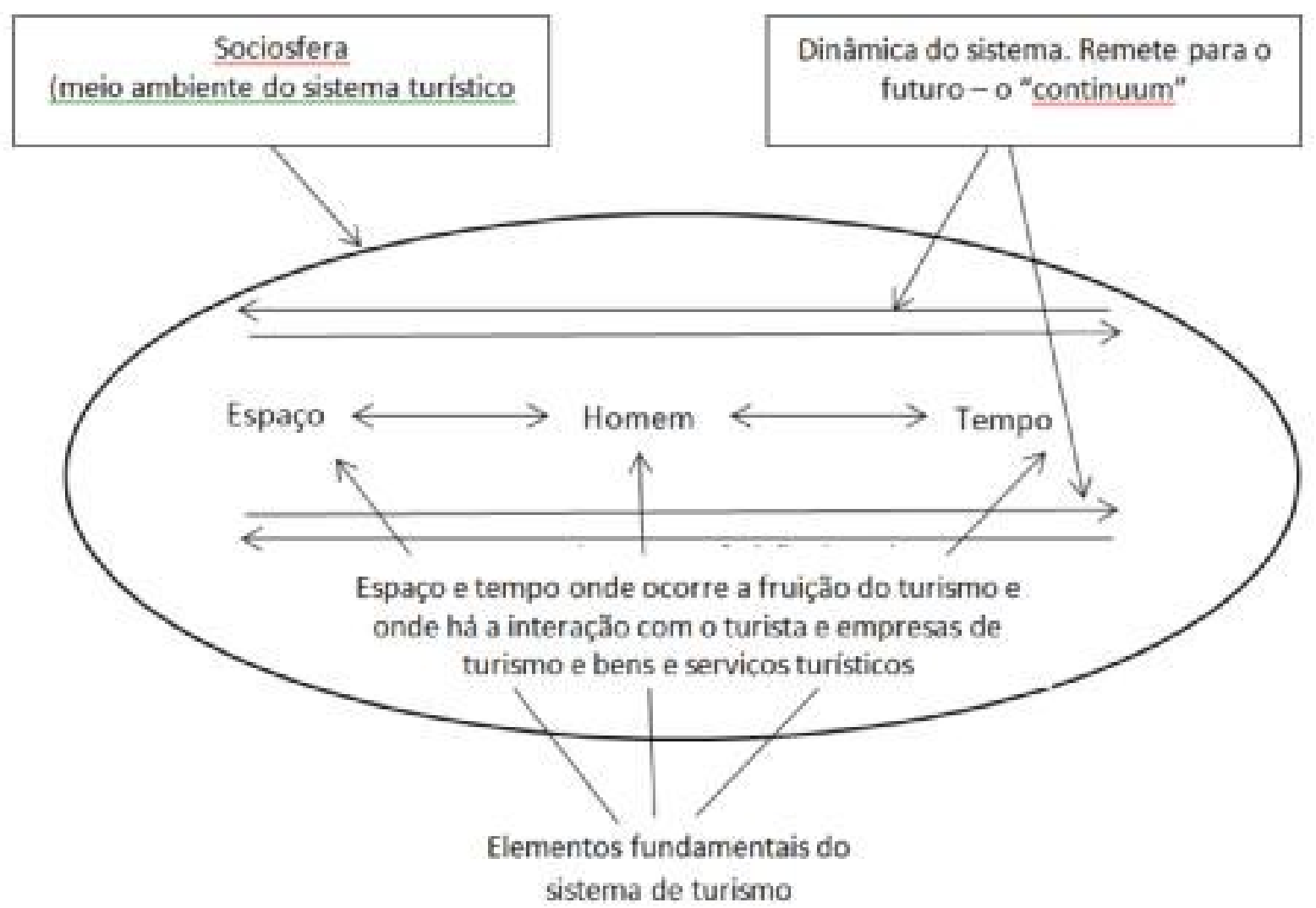

Fonte: Panosso Netto, 2005

Wahab (1988) traz, também, uma discussão a cerca do conceito de turismo, trazendo definições de turismo propostas por alguns autores e órgãos oficiais e propõe uma nova definição:

O turismo é uma atividade humana intencional que serve como meio de comunicação e como elo da interação entre povos, tanto dentro de um mesmo país como fora dos limites geográfico dos países. Envolve o deslocamento temporário de pessoas para outra região, país, ou continente, visando à satisfação de necessidades outras que não o exercício de uma função remunerada (Wahab, 1988, p.26).

Assim como Cuervo (1967), Wahab (1988) aponta o turismo como tendo a função de comunicação entre os povos, e meio de interação entre as nações. Consequentemente, se houver um correto funcionamento da atividade turística, como menciona Cuervo, pode levar a promoção da paz mundial. 
Por fim, ressalta-se que Wahab propõe a análise do turismo baseado no conceito de sistema, mas não aprofunda a análise desse sistema turístico por meio de seus elementos e inter-relações.

\subsection{Neil Leiper}

Neil Leiper nasceu na Austrália. Graduou-se em comércio e trabalhou boa parte de sua vida como consultor de negócios. Foi professor na Sydney Technical College (atualmente TAFE NSW - Sydney Institute); e professor na Massey University, na Nova Zelândia, durante a década de 1990, onde fez seu doutorado. Aposentou-se em 2006, como Professor da Escola de Turismo e Gestão Hoteleira na Southern Cross University (SCU). Após sua aposentadoria, trabalhou como professor pesquisador honorário na Narasuen University, na Tailândia. Faleceu em Fevereiro de 2010.

Durante seu percurso acadêmico, Leiper publicou dois livros: Tourism Management (1995) e Tourism systems: an interdiscplinary perspective (1990). Além de uma grande quantidade de artigos, curtos comentários, réplicas e críticas de livros publicados em diversas revistas científicas internacionais.

Para Hall (2010), o artigo "The Framework of tourism: towards a definition of tourism, tourist, and the tourist industry", publicado em 1979, na Annals of Tourism Research, foi um dos primeiros do autor a tratar da área de turismo. Hall (2010) afirma que este é, indiscutivelmente, seu estudo seminal, abordando temas chaves que irão marcar seus trabalhos, como a abordagem sistêmica, atrações, industrialização parcial e a utilização destes aspectos para uma estratégia para a gestão do turismo.

Nessa obra, Leiper (1979) dentifica três grupos de definições do turismo: econômicas, técnicas e holísticas. Leiper critica as definições econômicas por essas não incluírem o elemento humano, espacial e temporal do turismo. E se baseia nos três elementos que compõe o conceito de turismo de Wahab para fazer essa crítica.

Leiper afirma que uma análise do turismo por meio de um modelo sistêmico permite um estudo multidisciplinar e interdisciplinar, preenchendo a lacuna entre os dois campos da academia.

Tourism defined in a systems framework would enable of its basic facets to be identified. They become the elements of the system. Such an approach would facilitate multidisciplinary studies of particular aspects of tourism and more significantly would give interdisciplinary studies of various facets and perspectives a 
common point of reference; the division between the two camps of academic scholarship could be bridged. (Leiper, 1979, p.395)

Nesse sentido, assim como Cuervo (1967) e Leiper (1979) buscam a análise do turismo através do conceito de sistemas devido à complexidade do fenômeno e a necessidade de uma abordagem que consiga perceber e compreender os diversos aspectos ou elementos envolvidos no mesmo.

$\mathrm{Na}$ construção do seu sistema, Leiper é influenciado pelos estudos de Gunn (1972) sobre o planejamento de regiões turísticas, entendida por ele como uma visão holística do turismo.

\begin{abstract}
the designer has an opportunity for a closed system of tourism environment made up of the five components: people...in a market area with desire and ability to participate; attractions...offer activities for user participation; services and facilities... for users/support the activities; transportation...moves people to and from the attractions destinations; and information and directions...assists users in knowing, finding, enjoying (Gunn 1972 como citado em Leiper, 1979, p.394)
\end{abstract}

Essa abordagem de Gunn (1972) sugere o turismo como um sistema, composto de cinco elementos: pessoas, atrações, serviços, transporte e informação. Leiper (1979) critica o sistema de Gunn (1972) devido ao fato dele não reconhecer as interações dos elementos do sistema turístico com o meio ambiente em que se encontra, ou seja, vê o fenômeno turístico sob a perspectiva de um sistema fechado. No entanto, baseado na Teoria Geral dos Sistemas, de Bertalanffy (1968), Leiper (1979) afirma que há a necessidade de ver o turismo como um sistema aberto, no qual o mesmo se relaciona com diversos aspectos do meio em que está inserido. Ainda, o autor coloca que o sistema de Gunn omite a existência de uma indústria turística.

Leiper (1979) busca superar as falhas do sistema de Gunn (1972) e identifica quatro componentes da atividade turística: componente comportamental; geográfico, industrial e ambiental.

O componente comportamental se refere aos turistas, os quais são o elemento humano do turismo. Turista é definido por Leiper como "a person making a discretionary, temporary tour which involves at least one overnight stay away from the normal place of residence, excepting tour made for the primary purpose of earning remuneration from points en routes" (Leiper, 1979, p.396). Nesse sentido, Leiper abrange como turistas os viajantes com pelo menos um pernoite em um lugar fora do seu lugar de residência, incluindo os viajantes a negócio que não tenham como motivo primário ganhar dinheiro em pontos da viagem. 
Leiper, assim como Wahab, afirma que o turismo possui dois componentes baseado em Bukart e Medlik (1974): um dinâmico, que configura a viagem realizada pelo turista; e um estático, que configura a estadia do mesmo no destino. Nesse sentido, ele busca explicar que a atividade turística envolve tanto a viagem quanto à estada no local, e por isso a necessidade de estipular um pernoite na definição de turista, diferenciando-o dos excursionistas. Ele coloca, ainda, assim como Wahab (1988), que a mudança na rotina devido a pernoite fora de sua residência habitual tem grande influência no comportamento dos indivíduos, o que dá uma característica específica ao turismo.

Os componentes geográficos são os aspectos espaciais do turismo composto por três elementos: região de geração de turistas; região de destino do turista; e uma região ou rota de trânsito. A região geradora é o local de residência habitual do turista e onde começa e onde termina o ato turístico. A região de destino é a localidade que atrai os turistas para a estada temporária e onde ocorre a interação entre os povos. E a rota de trânsito é um caminho que liga a região geradora à região de destino, apontado por Leiper como um elemento vital, pois tem grande influência nos fluxos turísticos.

O componente industrial, por sua vez, compreende as empresas e serviços que visam atender as necessidades dos turistas. Leiper divide o componente industrial em seis setores:

(1) marketing turístico; (2) os transportes turísticos; (3) as acomodações turísticas; (4) as atrações turísticas, como por exemplo, pontos turísticos, eventos e determinados serviços; (5) diversos serviços turísticos, incluindo nesse setor, restaurantes, lojas de souvenir, seguros, entre outros; e (6) a regulação turística, que compreende os governos, instituições de educação, associações de empresas, etc. O componente industrial é visto por Leiper como uma cadeia interligada que abrange tanto a região geradora, quanto a de destino e a rota de trânsito, e cujas conexões permitem o fornecimento de produtos e serviços aos turistas.

Por fim, o componente ambiental se refere ao meio no qual ocorre o fenômeno turístico e todas as suas inter-relações com o mesmo. Ao final do seu trabalho, Leiper propõe uma nova definição para o turismo em que ele coloca o turismo como um sistema, definindo o componente deste:

It is the system involving the discretionary travel and temporary stay of persons away from their usual place of residence for one or more nights, excepting tour made for the primary purpose of earning remuneration from points en route. The elements of the system are tourist, generating regions, transit routes, destination regions and a tourist industry. These five elements are arranges in spatial and functional connections. Having the characteristics of an open system, the organization of five elements operates within broader environments: physical, cultural, social, economic, political, technological with which it interacts. (Leiper, 1979, p.403) 
Com base nessa definição, percebe-se que Leiper (1979), assim como Cuervo (1967) e Wahab (1988), vê o turismo como um sistema que surge devido ao deslocamento temporário de indivíduos de seu local de residência habitual para outra região. Leiper (1979) e Wahab (1988) apontam, ainda, um aspecto essencial para que esse deslocamento se configure como turismo, no qual o mesmo não deve ter como fim ganhar qualquer tipo de remuneração. $\mathrm{O}$ autor afirma ainda que o sistema turístico é um sistema aberto, pois ocorre inserido e interagindo com um ambiente maior: incluindo o ambiente físico, cultural social, econômico, político e tecnológico. Dessa forma, Leiper (1990), amplia as interações do turismo com o meio, pois além de relacionar o turismo com a sociosfera, a qual se referia Wahab (1988), inclui também as relações com a biosfera (meio físico) e a tecnosfera (meio tecnológico).

Leiper (1979), amparado nessa definição, propõe um modelo simbólico do que seria o sistema turístico, como mostra a Figura 03. Nele estão representados os quatros componentes do turismo: comportamental, geográfico, industrial e ambiental. O comportamental representado pelo elemento humano, o turista, se desloca saindo da região geradora, através da rota de trânsito para a região de destino e depois voltando para a região geradora. $\mathrm{O}$ elemento industrial é representado dentro dos elementos geográficos que são as regiões geradoras e de destino e a rota de trânsito. E o elemento ambiental é dentro do qual está inserido o sistema turístico e com o qual o mesmo se relaciona.

Figura 03: Sistema Turístico de Leiper

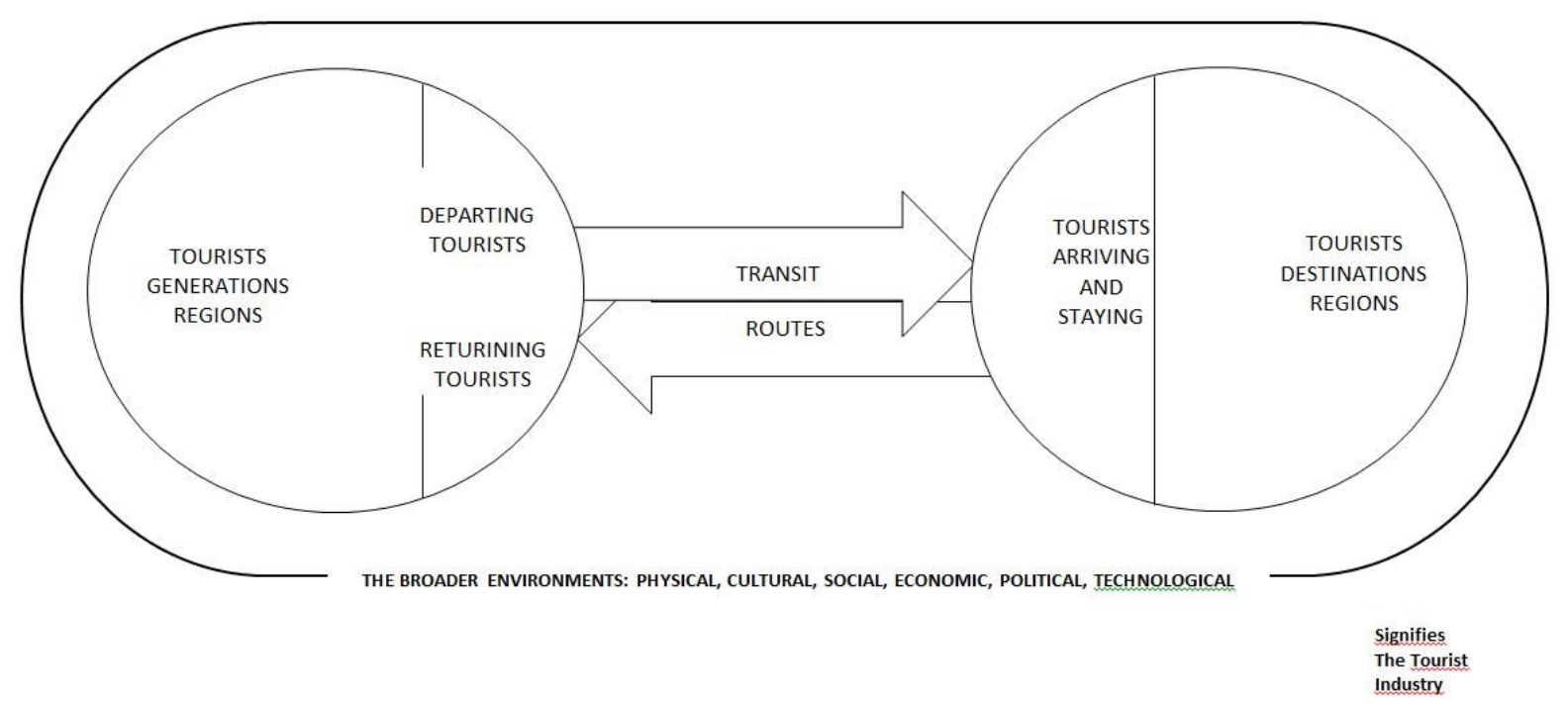

Fonte: Leiper, 1979 
O autor mostra que o estudo do turismo por meio de abordagem sistêmica é útil em diferentes áreas, tanto na área acadêmica, quanto na empresarial, assim como para o planejamento governamental.

Leiper (1990) afirma, no entanto, anos depois, que uma falha apresentada em seu trabalho é dele ter definido o turismo como um sistema, e que uma abordagem mais correta seria reconhecer que o turismo dá origem a sistemas turísticos. Ou seja, ele reconhece que o turismo não é em si um sistema, mas que esse fenômeno, quando ocorre, faz surgir um sistema turístico que envolve diversos elementos, relações e interações.

\section{CONSIDERAÇÕES FINAIS}

O sistemismo se constitui hoje no paradigma vigente, com grande influência nas pesquisas realizadas dentro dos estudos do turismo. No entanto, existem algumas lacunas que o paradigma sistêmico não consegue explicar. Por isso, o surgimento de novas abordagens que tentam superar esse paradigma.

Através desta análise pode-se perceber que os autores Raimundo Cuervo, Salah-Eldin Abdel Wahab e Neil Leiper tiveram uma enorme contribuição para as discussões sobre o turismo durante o período entre a década de 1960 e 1980. Suas obras romperam com os pensamentos acerca do turismo da época e propôs uma nova visão e uma nova abordagem que pudesse analisar o turismo em toda a sua complexidade.

Enquanto os estudos da época buscavam compreender o fenômeno turístico por meio de uma visão parcial e segmentada de disciplinas específicas, esses autores sugeriram um novo enfoque que compreendia o turismo como um todo complexo, composto por diversos elementos e que se relacionava com o meio em que estava inserido nas suas mais diversas formas: econômica, cultural, política, ambiental e tecnológica. Dessa forma, fundamentados no conceito de sistema, eles entenderam que o turismo seria melhor compreendido através de uma análise macroscópica do todo e da interação entre as partes.

Outra importante contribuição é a da ênfase dos autores no elemento humano do sistema turístico. Os três autores apontam o turista e o seu deslocamento, como o centro do sistema no qual sem o mesmo não é possível que exista o turismo. É através do deslocamento deste dentro do espaço que surgem diversas interações, relações e transformações que precisam ser estudadas, compreendidas, planejadas e monitoradas. 
Por fim, este artigo buscou evidenciar a necessidade de estudos a cerca da construção do conhecimento sobre o fenômeno turístico, pois estudos desta natureza fortalecem teorias, validam o conhecimento e definem o campo de abrangência da área.

\section{REFERÊNCIAS}

Acerenza, Miguel Ángel. (2002). Administração do turismo: conceituação e organização. (Vol. 1). Bauru: EDUSC.

Aledo, A., \& Domínguez, J. A. (2001). Problemas socioambientales II: Las Ecoutopías.

Aledo, A. \& Domínguez, J. A. (2001). Sociología ambiental. Granada: Grupo Editorial Universitario.

Azevedo, F. F., Figueiredo, S. L., Nóbrega, W. R. M., \& Maranhão, C. H. S. (2013). Turismo em Foco: Globalização e Políticas Públicas. In: Turismo em Foco. Belém: NAEA.

Bertalanffy, L. von. (1968). General System Theory: foundations, development, applications. New York: George Braziller.

Burkart, A.J. \& Medlik, S. (1974). Tourism. Past, Present and Future. London: Heinemann.

Capra, F. (1996). A teia da vida. (N. R. Eichemberg, Trad.) São Paulo: Cultrix.

Gil, A. C. (1985). Métodos e técnicas em pesquisa social.(6a ed.). São Paulo: Atlas.

Gil, A. C. (1991). Como elaborar projeto de pesquisa. (3a ed.). São Paulo: Atlas.

Hall, C. M. \& Page, S. (2010). The contribution of Neil Leiper to tourism studies. Current Issues in Tourism, 7 (13), 299-309.

Herrera, A. A.; Damian; A. G. (2013). Sustainable Tourism Management: Conceptual Bases And Cases Studies. México: Universidad de Quintana.

Kuhn, T. S. (2001). A Estrutura das Revoluções Científicas. (6a ed.). São Paulo: Perspectiva. International Academy for the Study of Tourism. (2009). Tribute to Salah Wahab. Quartely Newsletter. 19(2).

Leiper, N. (1979). The framework of tourism: Towards a definition of tourism, tourist, and the tourist industry. Annals of Tourism Research, 6(4), 390-407.

Leiper, N. (1990). Partial industrialization of tourism systems. Annals of Tourism Research, 17(4), 600-605.

Leite, F. T. (2008). Metodologia Científica: métodos e técnicas de pesquisa: monografias, dissertações, teses e livros. Aparecida, SP: Ideias \& Letras. 
Lohmann, G., \& Panosso Netto, A. (2008). Teoria do turismo: conceitos, modelos e sistemas. São Paulo: Aleph.

Panosso Netto, A. (2005). Filosofia do Turismo: teoria e epistemologia. São Paulo: Aleph.

Secretaria de turismo. (2000). Estudio de gran visión del turismo em Mexico - Perspectiva 2020. Ciudad del Mexico: Centro de Estudios Superiores.

Santos, J. A; Domingos, P. F. (2011). Metodologia Científica. (2a Ed). São Paulo: Cengage Learning.

Wahab, S. E. A. (1988). Introdução à administração do turismo: alguns aspectos estruturais e operacionais do turismo internacional: teoria e prática. (2a ed.). São Paulo: Pioneira. 